\title{
The pgip family in soybean and three other legume species: evidence for a birth-and-death model of evolution
}

\author{
Raviraj M Kalunke ${ }^{1 \dagger}$, Alberto Cenci ${ }^{2+}$, Chiara Volpi ${ }^{1,6 \dagger}$, Donal M O'Sullivan ${ }^{3,7}$, Luca Sella ${ }^{4}$, Francesco Favaron ${ }^{4}$,
} Felice Cervone ${ }^{5}$, Giulia De Lorenzo ${ }^{5}$ and Renato D'Ovidio ${ }^{{ }^{*}}$

\begin{abstract}
Background: Polygalacturonase-inhibiting proteins (PGIPs) are leucine-rich repeat (LRR) plant cell wall glycoproteins involved in plant immunity. They are typically encoded by gene families with a small number of gene copies whose evolutionary origin has been poorly investigated. Here we report the complete characterization of the full complement of the pgip family in soybean (Glycine max [L.] Merr.) and the characterization of the genomic region surrounding the pgip family in four legume species.

Results: BAC clone and genome sequence analyses showed that the soybean genome contains two pgip loci. Each locus is composed of three clustered genes that are induced following infection with the fungal pathogen Sclerotinia sclerotiorum (Lib.) de Bary, and remnant sequences of pgip genes. The analyzed homeologous soybean genomic regions (about $126 \mathrm{~Kb}$ ) that include the pgip loci are strongly conserved and this conservation extends also to the genomes of the legume species Phaseolus vulgaris L., Medicago truncatula Gaertn. and Cicer arietinum L., each containing a single pgip locus. Maximum likelihood-based gene trees suggest that the genes within the pgip clusters have independently undergone tandem duplication in each species.

Conclusions: The paleopolyploid soybean genome contains two pgip loci comprised in large and highly conserved duplicated regions, which are also conserved in bean, M. truncatula and C. arietinum. The genomic features of these legume pgip families suggest that the forces driving the evolution of pgip genes follow the birth-and-death model, similar to that proposed for the evolution of resistance (R) genes of NBS-LRR-type.
\end{abstract}

\section{Background}

The plant cell wall represents one of the main obstacles to the colonization of the plant tissue by microbial pathogens. To surmount this barrier, most fungal pathogens produce cell wall degrading enzymes (CWDEs), among which endo-polygalacturonases (PGs; EC 3.2.1.15) are secreted at very early stages of the infection process [1]. PGs cleave the $\alpha-(1-4)$ linkages between D-galacturonic acid residues in homogalacturonan, causing cell separation and maceration of host tissue. To counteract the

\footnotetext{
*Correspondence: dovidio@unitus.it

${ }^{\dagger}$ Equal contributors

'Dipartimento di Scienze e tecnologie per l'Agricoltura, le Foreste, la Natura e l'Energia, (DAFNE), Università della Tuscia, Via S. Camillo de Lellis snc,

01100, Viterbo, Italy

Full list of author information is available at the end of the article
}

activity of PGs, plants possess cell wall glycoproteins, called polygalacturonase-inhibiting proteins (PGIPs), the importance of which in defence has been demonstrated in different plant species [2-12].

Like the products of many resistance genes, PGIPs belong to the subclass of proteins containing leucine-rich repeats (LRRs) of the extracytoplasmic type (LxxLxLxxNxLT/ SGxIPxxLxxLxx) [13]. The LRR domain of PGIP is typically formed by 10 imperfect LRRs of 24 residues each and is responsible for the molecular interaction with PGs. The LRRs are organized to form two $\beta$-sheets, one of which (sheet B1) occupies the concave inner side of the molecule and contains residues crucial for PG recognition [14].

To counteract the many PGs produced by fungal pathogens, plants have evolved a variety of PGIPs with

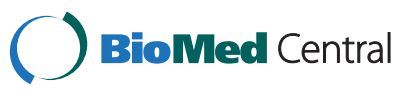


different specificities. Variability is present also within each plant species, since PGIPs are encoded by gene families, comprising 2 members in Arabidopsis thaliana [3] up to 16 in Brassica napus [15]. A clear example of intra-specific variation in the inhibition properties against fungal and insect PGs has been reported for members of the bean (Phaseolus vulgaris L.) pgip family [16]. Variation among different family members extends also to the regulation of their expression [17].

The soybean (Glycine max [L.] Merr.) pgip family is composed by at least four genes forming two clusters, one containing Gmpgip1 and Gmpgip2, separated by about $3 \mathrm{kbp}$, and the other containing Gmpgip3 and Gmpgip4, separated by a maximum distance of $60 \mathrm{Kbp}$ [18]. These findings are particularly interesting because soybean is a well-established paleopolyploid plant species. Consequently, the characterization of the full complement of the soybean pgip family could provide important information about the forces driving the evolution of this gene family.

In this study, we have characterized the complete set of pgip genes in the soybean genotype Williams 82 and demonstrated the existence of two pgip loci. The study was extended to other legume species by characterizing a region of about $140 \mathrm{~Kb}$, comprising the single pgip locus of bean, and the pgip regions in the recently released genomes of Medicago truncatula Gaertn. [19] and Cicer arietinum L. [20]. Comparative analysis between the pgip regions of these species suggests that the legume pgip family follows the birth-and-death model of evolution.

\section{Results}

Characterization of soybean BAC clones and isolation of two novel Gmpgip genes

Seven BAC clones, previously isolated from a soybean BAC library using a pgip probe, were analysed with primers specific for Gmpgip1, Gmpgip2, Gmpgip3 and Gmpgip4 [18]. None of the BAC clones contained all four pgip sequences together. Three of them (95O4, 85 M15, 28B18) contained both Gmpgip1 and Gmpgip2 and two (26I2, 6 F5) contained both Gmpgip3 and Gmpgip4. The remaining two BAC clones (1 F11, 62 K14) did not produce a clear amplicon with none of the Gmpgip primer combinations; therefore, they were not analyzed further. The size of the insert contained in each BAC clone, determined by pulsed-field gel electrophoresis (PFGE) following Not I digestion, varied between about $50 \mathrm{~Kb}$ and $190 \mathrm{~Kb}$ (Additional files 1 and 2). Fingerprinting of the BAC clones following HindIII digestion showed overlapping profiles for those containing Gmpgip1 and Gmpgip2 (95O4, $85 \mathrm{M} 15,28 \mathrm{~B} 18)$, and those containing Gmpgip3 and Gmpgip4 (26I2, 6 F5) (Additional file 1). BAC end sequencing and shotgun subcloning and sequencing identified two novel Gmpgip genes, one in the clone 85 M15 (Gmpgip5), the other in the clone $26 \mathrm{I} 2$ (Gmpgip7). Gmpgip5 was at the terminal end of 85 M15 and was partial; its complete sequence was obtained by PCR performed on genomic DNA. The coding regions of Gmpgip5 and Gmpgip7 contain uninterrupted open reading frames (ORFs) of 1008 and $1011 \mathrm{bp}$, respectively, including the stop codon. The predicted amino acid sequence of these two ORFs showed the typical PGIP structure, comprising a 21 amino acid signal peptide for secretion in the apoplast, 10 leucine rich repeats (LRRs) of about 24 amino acids each and eight cysteine residues, four each at $\mathrm{N}$ - and C-terminal part of the protein (Additional file 3).

Since fingerprint analysis indicated the lack of overlapping portions between the two sets of BAC clones, we hypothesized the existence of two pgip loci, one including Gmpgip1, Gmpgip2 and Gmpgip5, as identified in the BAC clone $85 \mathrm{M} 15$ and the other one including Gmpgip3, Gmpgip4 and Gmpgip7, as identified in the BAC clone 26I2. The recent availability of the soybean genome sequence [21] allowed us to confirm the existence of two pgip loci and to define the spatial distribution of the Gmpgip genes (see below).

\section{Transcript accumulation and in vitro inhibition assays of Gmpgip5 and Gmpgip7}

We have previously reported variation in the expression pattern of Gmpgip genes (Gmpgip1, Gmpgip2, Gmpgip3 and Gmpgip4) following infection of soybean hypocotyls with the necrotrophic fungal pathogen Sclerotinia sclerotiorum [18]. In this work, we extended the study to Gmpgip5 and Gmpgip7. qRT-PCR analysis showed that Gmpgip5 and Gmpip7 are expressed in soybean hypocotyls and are induced following the infection with S. sclerotiorum. The basal transcript levels of both Gmpgip5 and Gmpgip7 are much lower than that of Gmpgip3, used as control because it is the most highly expressed Gmpgip gene in soybean hypocotyls [18]; moreover, basal expression of Gmpgip7 was higher than that of Gmpgip5 (Table 1). Expression of Gmpgip5 decreases during the first 24 hour post infection (hpi) with S. sclerotiorum, to greatly increase by more than 1000 fold at $48 \mathrm{hpi}$, the last time point analyzed, when the tissue is almost completely macerated (Table 2). Upon infection, expression of Gmpgip7 shows a moderate increase during the first 24 hpi to reach high levels at 48 hpi (Table 2). Gmpgip3 showed different kinetics of transcript accumulation, with a maximum of five fold increase at $24 \mathrm{hpi}$ and no further increase at $48 \mathrm{~h}$ (Table 2).

Database searches confirmed the presence of expressed sequence tags (ESTs) corresponding to Gmpgip5 and Gmpgip7 and showed variation of their expression during development, with Gmpgip5 ESTs present in hypocotyls and pods and Gmpgip7 ESTs present in roots and stem (Additional file 4). ESTs for the remaining Gmpgip genes were also identified, with Gmpgip3 being the 
Table 1 Basal expression of Gmpgip5 and Gmpgip7 compared with Gmpgip 3 in soybean hypocotyls prior pathogen infection

\begin{tabular}{ll}
\hline Genes & Ct values $^{{ }^{\mathbf{~}}}$ \\
\hline Gmpgip3 & $19.83 \pm 1.00$ \\
Gmpgip5 & $32.68 \pm 0.94$ \\
Gmpgip7 & $24.65 \pm 0.88$ \\
GmELF1A & $17.13 \pm 1.01$
\end{tabular}

${ }^{a}$ Transcript levels were determined by quantitative RT-PCR. Gmpgip and GmELF1A (housekeeping) genes showed similar amplification efficiencies. Gmpgip3 crossed the detection of threshold 6 and 13 cycles before Gmpgip7 and Gmpgip5 transcripts, respectively. Means of $\mathrm{Ct}$ values are based on three technical replicates each of two biological replicates.

most represented in soybean tissues (Additional file 4). In particular, about twice more transcripts have been found in the hypocotyl for this gene compared to Gmpgip5, confirming the higher level of expression of Gmpgip3 shown by the qRT-PCR results (Table 1).

In order to verify the inhibition activities of Gmpgip5 and Gmpgip7 against fungal PGs, we have expressed these genes in Nicotiana benthamiana using a vector based on potato virus X (PVX; [22]). Western blot analyses on total protein extracts using an antibody raised against the bean PGIP showed the accumulation of GmPGIP7 and GmPGIP3, which was used as positive control (Additional file 5). On the contrary, no immunodecoration signal was detected in extracts prepared from control plants (non-inoculated or inoculated with the empty vector) (Additional file 5) or from plants infected with the PVX-Gmpgip5 construct (data not shown). Despite considerable effort, all PVX-based attempts to express GmPGIP5 failed.

Total protein extracts of $N$. benthamiana leaves infected with the PVX-Gmpgip7 were then used to test the inhibitory activity of GmPGIP7 against the fungal PGs of S. sclerotiorum, Fusarium graminearum, Colletotrichum acutatum and Aspergillus niger (data not shown). No

Table 2 Time-course expression analysis ${ }^{\mathrm{a}}$ of Gmpgip genes in etiolated soybean hypocotyls infected with S. sclerotiorum

\begin{tabular}{llll}
\hline \multirow{2}{*}{$\begin{array}{l}\text { Hours post } \\
\text { infection (hpi) }\end{array}$} & \multicolumn{3}{l}{ Relative expression } \\
\cline { 2 - 4 } & Gmpgip3 & Gmpgip5 & Gmpgip7 \\
\hline 8 & $1.16 \pm 0.55$ & $1.45 \pm 1.95$ & $4.38 \pm 1.30$ \\
16 & $2.30 \pm 0.891$ & $0.56 \pm 0.22$ & $5.78 \pm 0.17$ \\
24 & $5.76 \pm 2.02$ & $0.29 \pm 0.32$ & $6.98 \pm 5.06$ \\
48 & $5.89 \pm 2.69$ & $454.0 \pm 34.1$ & $265.5 \pm 32.01$ \\
\hline
\end{tabular}

${ }^{a}$ Analysis was performed by qRT-PCR. Gmpgip and housekeeping genes showed similar amplification efficiencies. Amplicon sizes: Gmpgip3 (211 bp); Gmpgip5 (194 bp); Gmpgip7 (200 bp); GmELF1A (195 bp).

${ }^{b}$ Quantification of gene expression was performed using the comparative $\mathrm{Ct}$ method (Livak and Schmittgen, 2001). Relative expression of each gene is reported as the fold increase of the transcript level in infected sample relative to each corresponding non-infected control sample and normalized with GMELF1A. inhibition was observed; on the contrary, all the PGs examined were inhibited by GmPGIP3, used as control (Additional file 5).

The soybean pgip genes are organized in two distinct loci Sequence comparison of the Gmpgip genes contained within the BAC clones and the assembled soybean genome sequence allowed us to confirm the presence of two pgip loci and to determine the arrangement of the Gmpgip genes within each of them. Each cluster of pgip genes spans a region of similar length (about 18 $\mathrm{Kb}$ ) on chromosome 5 (in order, Gmpgip5, Gmpgip2 and Gmpgip1) and chromosome 8 (Gmpgip7, Gmpgip3 and Gmpgip4). All genes are transcribed in the same direction (Figure 1). In addition to these transcribed pgip genes, two and one remnant sequences were found on chromosome 5 and 8, respectively. One of the remnants in the locus on chromosome 5 [Gmpgip* (1)] is heavily fragmented, whereas the other two, on chromosomes 5 [Gmpgip*(2)] and 8 (Gmpgip*) encode 65 residues of the $\mathrm{C}$-terminal region and 220 residues of the $\mathrm{N}$ - terminal and middle regions, respectively (Additional file 6).

Nucleotide sequences of regions the two soybean pgip loci were compared by a Bl2seq analysis, showing that the regions flanking the pgip loci are well conserved in nucleotide sequence and collinear in gene order and orientation (Figure 2). The main exception to this collinearity is represented by two major gaps in the alignment, due to LTR retrotransposon insertions in the locus on chromosome 5 (Figure 2). Notably, the region containing the Gmpgip copies shows the most exceptions to the sequence collinearity, as no clear diagonal is visible in this region and alignments are limited to the coding regions of different pgip members (Figure 2).

In the comparison between loci, only Gmpgip 1 and Gmpgip3, on the one side, and Gmpgip2 and Gmpgip7, on the other side, share similarity in the 3 ' regions, limited to the proximal $200 \mathrm{bp}$ sequences. The $5^{\prime}$ regions of the different Gmpgip genes are also strongly divergent and sequence divergence in these regions is reflected also in the composition of cis-elements. Sequence analysis. limited to known cis-acting elements regulating genes involved in the defence response, showed that all six Gmpgip genes contain sequences sharing identity with these elements; differing, however, in types and numbers. For example Gmpgip3 contains the highest number of W-box elements, whereas it lacks sequences matching BIHD1OS2 elements (Additional file 7).

\section{Structural analysis of the bean pgip locus}

For the characterization of the bean pgip locus, the bean BAC clones $129 \mathrm{~F} 4$ and 10G1 spanning the bean pgip locus were isolated from a genomic library prepared 
from BAT93 genotype. The $129 \mathrm{~F} 4$ and 10G1 clones contain an insert of about $37150 \mathrm{bp}$ and $107473 \mathrm{bp}$, respectively, with an overlapping segment of 5201 bp [16]. These clones were completely sequenced allowing the characterization of a total of $139420 \mathrm{bp}$, with the pgip region spanning about $50 \mathrm{~Kb}$. This region represents the only pgip locus present in the bean genome and contains four intronless Pvpgip genes (Pvpgip1Bat, Pvpgip2Bat, Pvpgip3Bat and Pvpgip4Bat) transcribed in the same direction [16].

The assembled BAC sequence of $P$. vulgaris BAT93 was mapped in two different genomic regions of the recently available genome sequence of $P$. vulgaris accession G19833. A major portion of the assembled BAT93 sequence (1..126624) was mapped on chromosome 2 [complement (36019507..36152120)] and shown to contain several annotated genes (from Phvul.002G200800.1 to Phvul.002G201900.1), whereas the remaining $13 \mathrm{~Kb}$ were mapped on chromosome 1 (49570303..49583535) and did not contain annotated genes. Three hypotheses can be made to explain this discrepancy: 1) the BAC 10G1 that contains the two regions is chimeric, i.e. two independent portions of BAT93 genome were cloned in the same BAC; 2) an assembly error, involving the analyzed regions, is present in the whole genome sequence, and 3) a translocation took place that differentiated the $P$. vulgaris BAT3 and G19833 accessions. Since the shorter region accounts only for about $10 \%$ of the entire BAC assembled sequence and shows a potentially different origin from the main BAC sequence assembly, we excluded it from subsequent analyses.

In order to analyze the structure of the region containing the bean pgip genes, a Blast2seq analysis (sequence aligned with itself), limited to the first $62 \mathrm{~Kb}$ of the assembled sequence that contain the four bean pgip genes, was performed. In addition to the diagonal alignment, several short alignments are present (Additional file 8). These include two retrotransposable elements (positions around $10 \mathrm{~Kb}$ and $40 \mathrm{~Kb}$ ), which showed off-diagonal alignment of their Long Tandem Repeats (LTRs), as tipically shown by LTR retrotransposon ends (Additional file 8). The four pgip genes align to each other, and alignment extending beyond the coding regions was observed only between PvBpgip1 and PvBpgip2 and between PvBpgip3 and PvBpgip4 (Additional file 8). Conversely, the alignment between pgip pairs PvBpgip1/ PvBpgip3, PvBpgip2/PvBpgip3, PvBpgip1/PvBpgip4, and PvBpgip2/PvBpgip4 is limited to the coding regions.

\section{Comparison of pgip loci in four Fabaceae species}

The assembled bean sequence (1..126624) containing the cluster of pgip genes was compared with the soybean genome and with the recent genome sequence releases of M. truncatula [19] and C. arietinum [20]. Like in bean, the genomes of $M$. truncatula and $C$. arietinum contain only one pgip locus. The pgip locus of $M$. truncatula spans a region of about $25 \mathrm{~Kb}$ containing a cluster of two genes with uninterrupted open reading frames (MTR_119s0023, Mtpgip1; MTR_119s0021, Mtpgip2), one possible pseudogene, annotated with an intron of $40 \mathrm{bp}$ to restore the correct open reading frame (MTR_119s0017, Mtpgip3), and one remnant corresponding to a sequence encoding a $\mathrm{C}$-terminal 53 residue PGIP fragment. The products encoded by Mtpgip1 Mtpgip2 and Mtpgip3 are shown in Additional file 9. They all contain a signal peptide for secretion to the apoplast, the typical 10 LRRs and eight cysteine residues, four each in $\mathrm{N}$ - and C-terminal portion of the protein; MtPGIP1 contains an additional cysteine in the $\mathrm{C}$-terminal region (Additional file 9). Similarly, the pgip locus of $C$. arietinum spans a region of about $30 \mathrm{~K}$ and contains two pgip genes (Additional file 10), one of which (LOC101504619, Capgip2) is interrupted by a fragment of about $17 \mathrm{~Kb}$ in the middle of the coding region. The putative protein encoded by Capgip1 (LOC101505245) also contains the typical PGIP features described above (Additional file 10). Taken together, these sequence analyses highlight that the typical PGIP structure is strongly conserved among and within all these pgip families. This conservation is accompanied, as expected, by the typical variation within LRRs composing each protein, and LRRs of different proteins.

Sequence comparison between the flanking regions of the pgip clusters in all four species, showed few genes and a very well conserved order, with few exceptions. Of the ten bean genes flanking the pgip cluster, only Pv_202000 and Pv_201300 are not conserved in all four legume species (Figure 3). Moreover, Pv_201200 and Pv_201100 exist as duplicated genes only in the bean genome, and Pv 202100 was lost in soybean chromosome 8 (Figure 3 ).

PGIP protein sequences from these four Fabaceae species ( $P$. vulgaris, G. max, $M$. truncatula, and $C$. arietinum) were aligned by MUSCLE and a phylogenetic tree was constructed by a Maximum likelihood approach (PhyML). As shown in Figure 4, the unrooted tree revealed that: i) $M$. truncatula and $C$. arietinum pgip copies are in species-specific clusters, suggesting that copy amplification took place after the divergence of species; ii) the $M$. truncatula and $C$. arietinum pgip clusters are close to each other and form a very well supported cluster; iii) the G. max and P. vulgaris pgip members are in a different cluster, consistent with the general taxonomic relationships of these members of the Fabaceae. Furthermore, G. max and P. vulgaris genes are distributed in three main clusters: a) a cluster including PvBPGIP1, PvBPGIP2 and GmPGIP3; b) a cluster including PvBPGIP3 and PvBPGIP4 and c) a cluster containing the remaining G. $\max$ genes. 


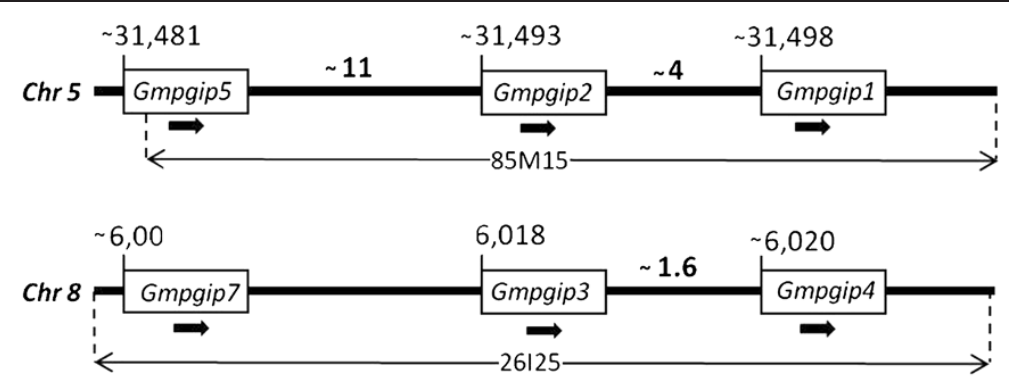

Figure 1 Genomic organization of the pgip gene family in soybean cv. Williams $\mathbf{8 2}$. Schematic representation of the arrangement of the Gmpgip genes in the two loci of the soybean genome. Regions covered by the BAC clones 85 M15 and 2612 on chromosomes 5 and 8 , respectively, are indicated. On the basis of the soybean genome database, 85 M15 starts and ends at 31,481,533 bp and 31,579,062 bp, respectively, whereas 2612 starts and ends at 5,980,885 and 6,108,916, respectively. Numbers between the genes represent distances in $\mathrm{kb}$ as determined on the soybean genome database. Arrows indicate the direction of the coding region from ATG to stop codon. Boxes are not in scale. Chr, chromosome.

\section{Discussion}

In this work, we have demonstrated that the full complement of the soybean pgip family is composed of six transcribed genes located in two different loci in the subterminal and terminal regions of chromosomes 5 and 8, respectively. Each pgip locus contains both complete and disrupted coding regions indicating that a pseudogenization ("death") process is active in the family. As assumed for NBS-LRR $R$-genes [23], the clusters of recently duplicated pgip copies should provide a reservoir of genetic variation from which novel pgip genes can evolve. The resemblance to NBS-LRR $R$-genes is further supported by previous findings showing that variation between pgip genes of different species or copies within a gene family is mainly due to single substitutions within the
LRR domain and in particular in the xxLxLxx solventexposed region $[15,16,18,24]$. Like in $R$-genes, models of codon evolution suggest the presence, in the solvent-exposed region of PGIP, of sites under positive selection [25-27], and functional analysis demonstrated that single substitutions or a short deletion within this region can cause changes in the inhibition properties of PGIP against fungal PGs [16,28-33].

An interesting feature of the soybean pgip loci, which are included in a larger duplicated region, is the high sequence conservation of the regions surrounding the pgip clusters that contrasts with the variability in the intergenic regions between pgip genes. Differences in the regions external to the pgip gene clusters are limited to small indels and to the presence of two transposable

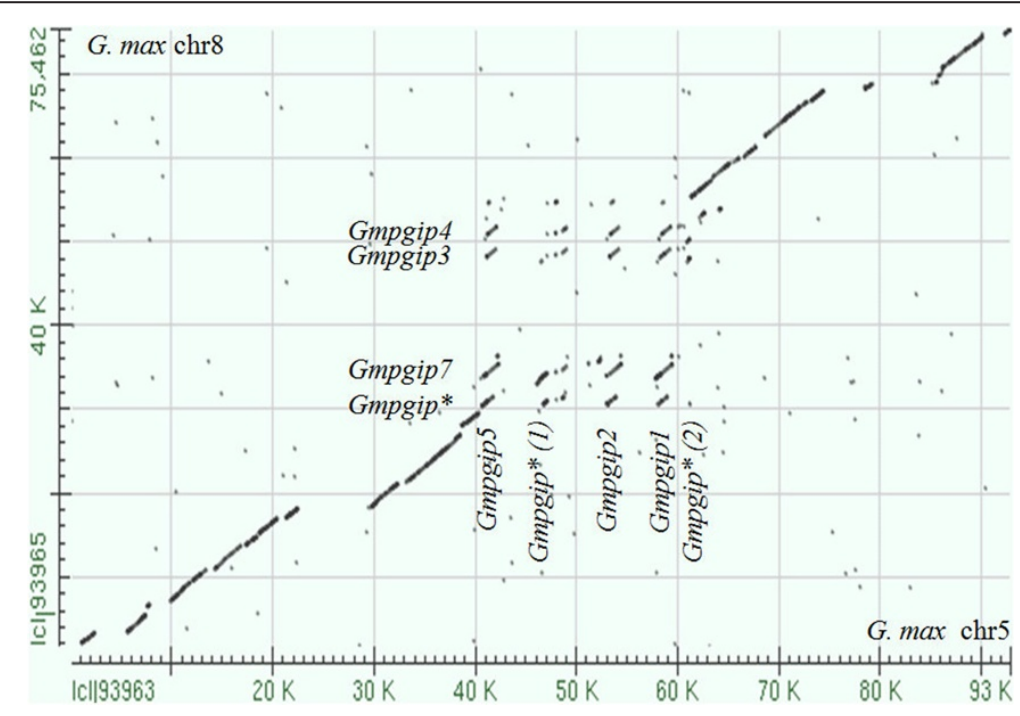

Figure $2 \mathrm{Bl}$ 2seq alignment analysis of the genomic regions encompassing the two pgip loci of G. max. Bl2seq analysis was performed between the pgip region $(-96 \mathrm{~Kb})$ in chromosome 5 and that $(-75 \mathrm{~Kb})$ in chromosome 8. Regions flanking the pgip loci are collinear in gene order, orientation as well as nucleotide sequence. ${ }^{*}$, remnant; Chr, Chromosome. 


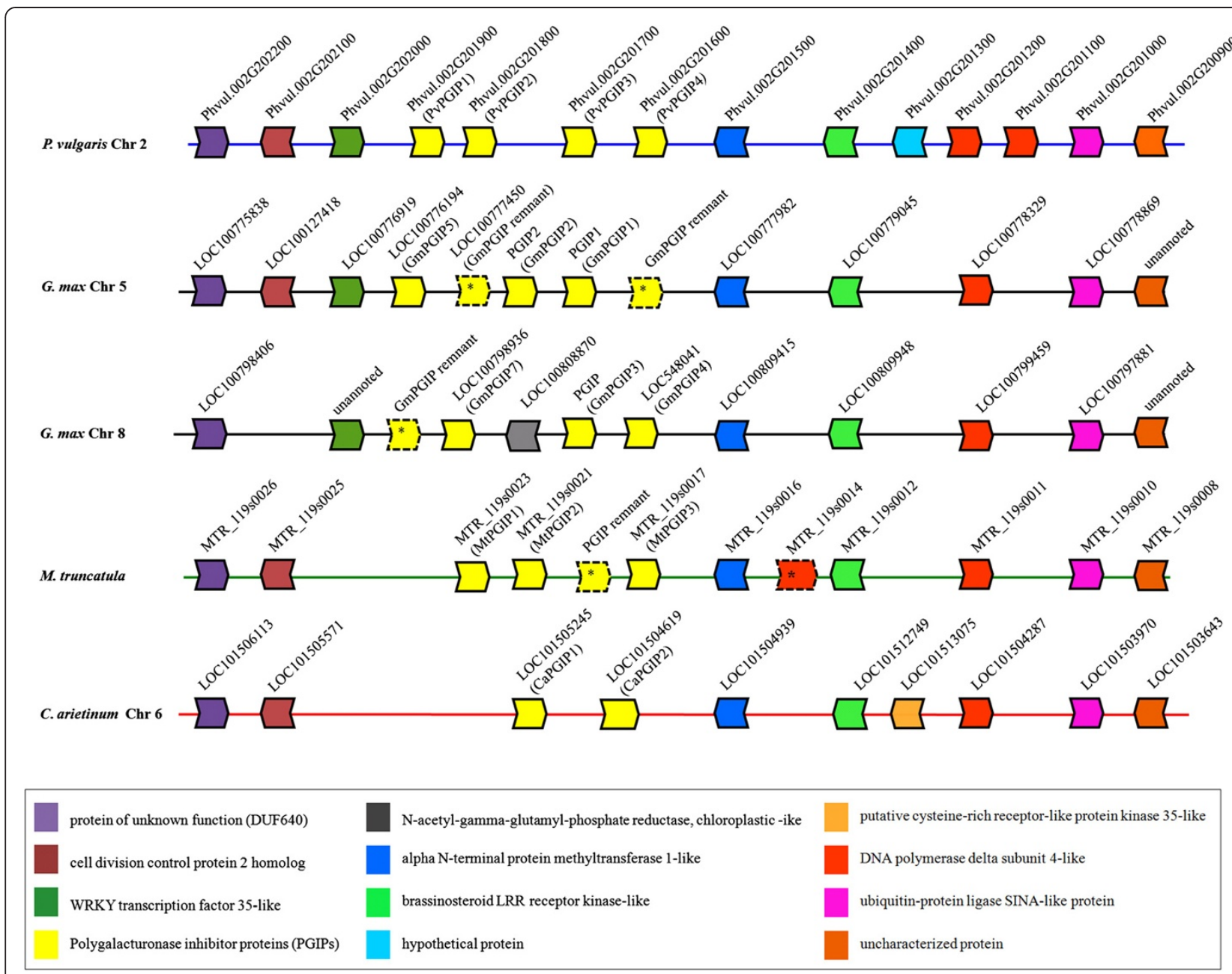

Figure 3 Schematic representation of genomic regions containing the pgip loci in Fabaceae species. Genomic regions containing the pgip loci were analysed for their shared synteny. Each block-arrow represents a predicted gene and the direction of the coding region from ATG to stop codon. Colored block-arrows are genes with a homolog. The gray block-arrow indicates a gene with no homolog. Genomic position from the left to the right element: P. vulgaris chromosome 2 (36,203,534 to 36,041,993 bp), G. max chromosome 5 (31,445,987 to 31,542,227 bp), G. max chromosome 8 (59,75,212 to 60,52,779 bp), M. truncatula (unplaced genomic scaffold 119) and C. aretinum (14,308,467, complement to 14,227,083 bp). *, remnant; Chr, chromosome.

elements only in the region of chromosome 8 . This conserved organization is typical of the paleopolyploid soybean genome, which underwent two rounds of Whole Genome Duplication (WGD) [34,35]. Recent analysis of the complete soybean genome sequence has revealed that indeed this is composed to a large extent by blocks of duplicated genes [21]; however. before the availability of the complete assembled soybean genome, data had indicated that the soybean genome was a mosaic of alternating homeologous regions retaining high sequence conservation and regions showing very low conservation [35].

In the homeologous regions containing the pgip clusters, the striking conservation is interrupted only by the remarkable sequence variability in the intergenic regions between the pgip genes. This low sequence conservation includes the proximal $5^{\prime}$ flanking regions, suggesting a differential regulation of the different pgip genes. Indeed, the six pgip genes show variation in cis-acting elements known to regulate defense response genes, and their expression patterns following pathogen infection show clear differences. The two novel pgip genes, Gmpgip5 and Gmpgip7, are poorly expressed in soybean hypocotyls but are strongly induced at late stages of infection with the fungal pathogen S. sclerotiorum. This expression pattern is similar to that of Gmpgip2 and differs from that of Gmpgip1, Gmpgip3 and Gmpgip4, which all show a more prompt induction following S. sclerotiorum infection [18]. Diversification of gene regulation following fungal pathogen infections or stress stimuli has been reported for other pgip gene families, including those of Arabidopsis [3], bean [16] and B. napus [15], and 


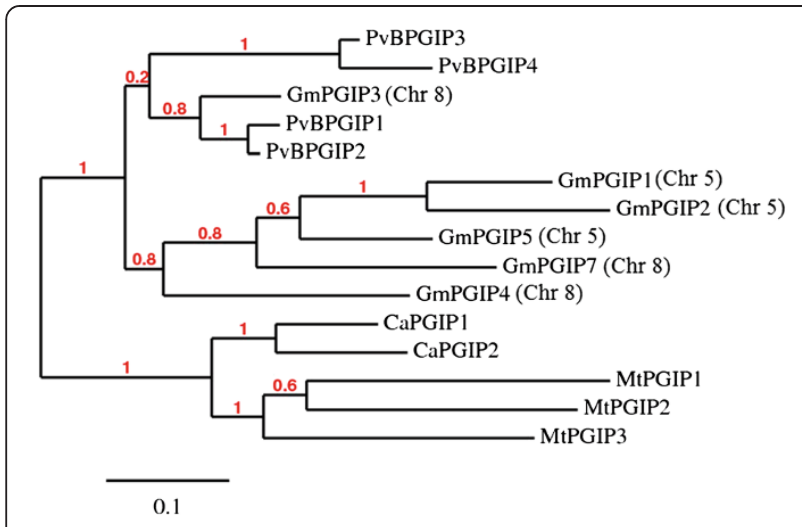

Figure 4 Phylogenetic tree showing the relationship among different PGIPs from Fabaceae species. The unrooted tree was constructed by a Maximum likelihood approach (PhyML) using the deduced amino acid sequences. Gm, Glycine max; PvB, Phaseolus vulgaris; Mt, Medicago truncatula; Ca, Cicer aretinum; Chr, Chromosome.

suggests adaptation against stresses. However, this possibility in soybean is still poorly supported at the protein level, since, at present, inhibition activity against fungal PGs has been shown in vitro only for the product encoded by Gmpgip3, which is also the most expressed soybean family member [18]. In fact, although GmPGIP1, GmPGIP2 and GmPGIP4 [18] and now also GmPGIP7 were expressed in $N$. benthamiana using PVX as a vector, they did not show any inhibitory activity. The lack of in vitro inhibition activity of GmPGIPs does not exclude the possibility that they can inhibit PGs from different sources not yet examined, or that only the in planta environment provides a suitable context to support the interaction with PGs. This last possibility has been suggested by Joubert et al. [6] who found a reduction of symptoms caused by the activity of Botrytis cinerea BcPG2 on plant tissue when co-infiltrated with Vitis vinifera VvPGIP1, although no interaction between VvPGIP1 and BcPG2 was detected in vitro. Moreover, as suggested previously [18], the lack of inhibition activity by GmPGIP1, GmPGIP2 GmPGIP4 and now GmPGIP7 towards fungal PGs may reflect a different physiological role in planta. This possibility is supported by several observations in different plant species. For example, OsFOR1, a rice protein possessing PG inhibiting capabilities, affects the formation and/or maintenance of floral organ primordia in rice [36]; levels of PGIP1 determine the timing of radicle protrusion in Arabidopsis [37], and Vvpgip1 can affect gene expression and cell wall structure in transgenic tobacco plants [38,39].

The genomic regions encompassing the pgip genes of soybean were also compared to the corresponding region of bean, which shares a very close phylogenetic relationship with soybean. The pgip gene family of the bean genotype BAT93, which comprises four clustered paralogs, has been previously characterized [16]. We have now extended the analysis to the bean BAT93 sequences flanking the pgip cluster and found a very strong conservation in the distribution of the genes compared to duplicated soybean regions encompassing the pgip loci. Of the ten bean genes flanking the pgip cluster, seven were conserved in both soybean chromosomes 5 and 8 . Pv_202100 was lost only on soybean chromosome 8, and the duplicated bean genes Pv_201200 and Pv_201100 exist as a single copy in both soybean chromosome 5 and 8 .

Conservation of the genomic pgip region is also evident in the more distantly related legume species $M$. truncatula and C. arietinum, whose assembled genomes have been recently released $[19,20]$. Both species possess a single pgip locus, with a cluster organization of the paralogs, and regions flanking the pgip array that maintain the strongly conserved distribution of the genes observed in the soybean and bean. Of the ten bean genes that surround the pgip cluster, seven are conserved in all four legume species. The finding that most of the pgip genes are organized in species-specific phylogenetic clusters indicates that the pgip copies within each cluster were independently formed after speciation. An exception to this observation is represented by GmPGIP3, PvPGIP1 and PvPGIP2. In fact, the soybean and bean PGIPs form separated clusters in maximum likelihood-based gene trees and, within the bean cluster, the four PvPGIPs form two well separated groups. However, as previously highlighted [16,18], the soybean GmPGIP3 groups with PvPGIP1 and PvPGIP2, suggesting that the duplication originating the ancestors of PvPGIP1/PvPGIP2 and PvPGIP3/PvPGIP4 took place before the separation of Glycine and Phaseolus lineages. In this context, it is noteworthy that the high sequence conservation of PvPGIP2 extends across a range of $P$. vulgaris germplasm and other Phaseolus species, suggesting an adaptive significance [30].

\section{Conclusions}

The paleopolyploid soybean genome contains two pgip loci comprised in large and highly conserved duplicated regions, likely originating from WGD. The region encompassing the pgip locus is also conserved in bean, M. truncatula and C. arietinum. The genomic features of these legume pgip families, which include inferred recent duplications and pseudogenization of pgip copies, suggest that the forces driving the evolution of pgip genes follow the birth-anddeath model, similarly to that proposed for the evolution of NBS-LRR-type $R$ genes [23].

\section{Methods}

\section{Plant material and infection experiments}

Soybean seeds (G. $\max$ [L.] Merr. cv. Williams 82) were germinated by placing them on previously sterilized and 
soaked paper towels which were then rolled and incubated for five days in the dark at $24^{\circ} \mathrm{C}$.

The B-24 isolate of S. sclerotiorum (Lib. De Bary) was grown for three days at $24^{\circ} \mathrm{C}$ on potato dextrose agar to obtain mycelium for the inoculation of soybean seedlings.

Infection experiments were performed by inoculating the middle region of etiolated soybean hypocotyls with actively growing mycelium of $S$. sclerotiorum as described by Favaron et al. [40]. Soybean seedlings were placed horizontally on plastic trays. Roots were covered with a layer of moist paper towel. Plants were inoculated by placing small plugs $(5 \times 2 \mathrm{~mm})$ of mycelium-colonized agar, cut from marginal zones of actively growing colonies, along the middle region of hypocotyls. Control soybean seedlings were mock inoculated with sterile agar medium. After incubated at $24^{\circ} \mathrm{C}$ in the dark hypocotyl segments (approximately $5 \mathrm{~mm}$ ) cut transversally with a razor blade exactly below the agar plugs were collected at $0,8,16,24$, and $48 \mathrm{~h}$ after inoculation, frozen in liquid nitrogen and stored at $-80^{\circ} \mathrm{C}$ for subsequent analyses. Lesion of the tissue increased during time and at $48 \mathrm{hpi}$ it affected most part of the hypocotyls as reported by Favaron et al. [40]. Two independent infection experiments were performed.

\section{RNA extraction and RT-PCR analysis}

Total RNA was extracted using RNeasy Plant Mini Kit (Qiagen, Italy) according to manufacturer's instructions. RNA concentration was determined both spectrophotometrically and by densitometric analysis of rRNA fragment following agarose gel electrophoresis. QuantiTect ${ }^{\circ}$ Reverse Transcription Kit (Qiagen) was used to remove genomic DNA contamination and to synthesize cDNA. Elimination of genomic DNA from cDNA preparation was verified by PCR with primers aligned in different exons for gene Translation elongation factor (GmELF1A) and Glucose-6-phosphate dehydrogenase (GmG6PD) as described by Miranda et al. [41].

The quantitative real-time PCR experiments were performed using the iCycler (Bio-Rad, Italy) and using master mix iQTMSYBER Green Supermix (BioRad, Italy), containing the SYBR Green I DNA binding dye. Each reaction was made in triplicate. Primers were designed using Primer 3 software (http://fokker.wi.mit.edu/primer3/, [42]) on the basis of the Gmpgip genes and have the following sequences (sense and antisense, respectively): Gm PGIP3-3 F 5'-ACCCCAACCCTAATCGGTCA-3' and GmPGIP3-3R 5' -AGGTGATTCCGACGAGATTG-3' for Gmpgip3; GmPGIP5-1 F 5'-ACCGGACTCCTTCG GCTACTTCC-3' and GmPGIP5-1R 5'- TGTTTCCC AGATACATGTGCC-3' for Gmpgip5; GmPGIP7-1 F 5' - TAAGGGTGTCAAAGACCTTGTT-3' and GmPG IP7-1R 5' - CACTTGTTATGAGCGTACAGC-3' for Gmpgip7; GmELF1A-F 5'-GACCTTCTTCGTTTCTC GCA-3' and GmELF1A-R 5'-GAACCTCTCAATCAC
ACGC-3' for GmELF1A [41]. Total reaction volume was $20 \mu \mathrm{l}$ and included $10 \mu \mathrm{l}(2 \times)$ master mix, $100 \mathrm{ng}$ of cDNA, $0.5 \mu \mathrm{l}(10 \mu \mathrm{M})$ of each forward and reverse primers and volume was adjusted with water. The PCR reaction conditions were: one cycle at $50^{\circ} \mathrm{C}$ for $2 \mathrm{~min}$, $94^{\circ} \mathrm{C}$ for $15 \mathrm{~min}$, then 40 cycles at $95^{\circ} \mathrm{C}$ for $15 \mathrm{sec}, 60^{\circ} \mathrm{C}$ for $50 \mathrm{sec}$ and $72^{\circ} \mathrm{C}$ for $50 \mathrm{sec}$. Primer specificity was confirmed by nucleotide sequencing (MWG, Germany) of amplicon. The Ct values of target genes (Gmpgip3, Gmpgip5 and Gmpgip7) and reference gene (GmELF1A) were used for further relative expression analysis by using the $2^{-{ }^{-} \Delta} \mathrm{CT}$ method [43]. Relative induction level was relative to the corresponding non infected sample at each time point analyzed. Calculation and statistical analyses were performed by Gene Expression Macro $^{\mathrm{Tm}}$ Version 1.1 (Bio-Rad, Italy). The qRT-PCR experiments included three replicas for each sample in two different biological replicas. PCR efficiency $(\varepsilon)$ was calculated for each gene from the slope of linear-regression of the threshold cycle versus log dilution serial of the cDNA according to equation $\varepsilon=\left(10^{\wedge}(-1 / \text { slope })-1\right)^{* *} 100$.

\section{PVX-mediated expression of GmPGIP5 and GmPGIP7, and immunoblotting}

The coding region of Gmpgip5 and Gmpgip7 was amplified by PCR with primers including restriction sites for $\mathrm{ClaI}$ and SalI or NruI at the 5' and 3' ends, respectively. The amplified fragments were double digested with ClaI and SalI or NruI and cloned into corresponding sites of the pPVX201 expression vector. The plasmids obtained were used to inoculate $N$. benthamiana plants using $30 \mu \mathrm{g}$ of plasmid DNA per plant as described by Baulcombe et al. [22]. Transiently expressed GmPGIP7 was extracted from leaves of $N$. benthamiana plants infected with single PVX-Pgip constructs or with the empty vector. Leaves were homogenized in $1 \mathrm{M} \mathrm{NaCl}(2 \mathrm{ml} / \mathrm{g})$, incubated with gentle shaking for $1 \mathrm{~h}$ at $4^{\circ} \mathrm{C}$, and centrifuged $20 \mathrm{~min}$ at 10,000 g. Supernatant was filtered through Miracloth (Calchem, USA), centrifuged to remove debris and stored at $-20^{\circ} \mathrm{C}$. Protein concentration was determined with the Coomassie Plus ${ }^{\mathrm{mm}}$ (Bradford) assay kit (Pierce, Rockford, IL, USA). SDS-PAGE and immunoblotting were performed as previously described [18]. Polyclonal antibodies raised against bean PGIP were used for immunoblotting experiments.

\section{Fungal growth, PG preparation and enzymatic assays}

Fungal growth and PG preparation were performed as previously described for A. niger [44], S. sclerotiorum isolate B-24 [45], and C. acutatum isolate SHK788 [16]. F. graminearum isolate 3827 [46]. Inhibitory activity of PGIP was performed as previously described by D'Ovidio et al. [18]. PG activity was expressed as reducing units (RU). One RU was defined as the amount of enzyme 
required to release reducing groups at $1 \mu \mathrm{mol} \mathrm{min}{ }^{-1}$ using D-galacturonic acid as standard.

\section{Screening of genomic libraries and sequencing}

The Bacterial artificial chromosome (BAC) library (prepared from G. max cv. Williams 82) was purchased from the Clemson University Genomics Institute (CUGI; Clemson, SC, USA). Screening and sequencing of BAC clone was performed as previously described by D'Ovidio et al. [18]. The bean BAC clones $129 \mathrm{~F} 4$ and 10G1 spanning the bean pgip locus were isolated from 16.603 recombinant clones of a genomic library prepared from BAT93 genotype [16].

Sequencing reactions were performed using the "ABI PRISM dye terminator cycle sequencing ready reaction" kit and DNA sequences were determined with the semiautomatic ABI PRISM 310 sequencer (Applied Biosystem, Monza, Italy). Sequences were also determined through the MWG-BIOTECH AG (Ebersberg, Germany) and PRIMM Srl. Sequencing Services (Milano, Italy).

\section{Nucleic acid manipulation and amino sequence analysis}

Nucleic acid manipulation, PCR, and cloning were performed according to the standard procedures [47]. DNAMAN software (Lynnon, BioSoft, Quebec, Canada) was used for nucleotide and amino acid sequence analyses. Signal peptide for GmPGIP5 and GmPGIP7 was predicted using http://wolfpsort.org/ [48]. The 5' flanking region of Gmpgip genes was scanned for presence of the cis-elements using PLACE (http://www.dna.affrc.go. jp/PLACE/signalscan.html), a database of plant Cis-acting regulatory DNA elements [49].

\section{Phylogenetic analysis}

BLASTp analysis was performed by using bean PGIP sequences to identify the already annotated PGIP genes and detect the occurrence of partial PGIP sequences (remnants) in G. max, M. truncatula and C. arietinum genomes.

The PGIP protein sequences from the four Fabaceae species (P. vulgaris, G. max, M. truncatula, and C. arietinum) were aligned by MUltiple Sequence Comparison by Log- Expectation (MUSCLE) and used for reconstructing phylogenetic tree. This was performed on web interface www.phylogeny.fr [50], using the PhyML software based on the Maximum likelihood principle.

\section{Comparative analysis}

The assembled sequences of the BAC clones $129 \mathrm{~F} 4$ and 10G1 (accession number HG964426) from the $P$. vulgaris genotype BAT93 were mapped in the $P$. vulgaris genome sequence by Bl2seq using the www. phytozome.org web interface.

Protein sequences of the genes spanning from Phvul.002G200900.1 to Phvul.002G202200.1 on the bean genome sequence were used as query in Bl2seq to detect most similar sequences in the sequenced genomes of G. max, C. arietinum and M. truncatula.

\section{Additional files}

Additional file 1: Insert size estimation of soybean BAC clones and fingerprinting analysis. A) The size of soybean BAC clones was determined by pulsed-field gel electrophoresis (PFGE) following the Notl digestion. 1, 2612; 2, 9504; 3, 6 F5; 4, 28B18; 5, 85 M15. M1 and M2 indicate the PFGE molecular mass ladder and Lambda-DNA/Hindlll ladder, respectively. B) Fingerprinting analysis. BAC clones were digested with Hind III and separated using 1.0\% agarose gel. 1, 6 F5; 2, 28B18; 3, 9504; 4, 26l2; 5, 85 M15; M, 1 kb DNA ladder.

Additional file 2: BAC clones isolated by screening a BAC library of G. max cv. Williams $\mathbf{8 2}$ using a soybean pgip probe. Insert size was determined by pulsed-field gel electrophoresis (PFGE) following Notl digestion. Additional file 3: Alignment of the deduced amino acid sequences of G. max PGIPs. Numbering is referred to the GmPGIP1 sequence and starts from the first residue of the mature protein. Regions A-D were predicted according to crystallographic analysis of the bean PVPGIP2 (Di Matteo et al. 2003, Proceedings of the National Academy of Sciences, 100, 10124-10128). The XXLXLXx region is boxed. Empty spaces have been added to better show identity/similarity among LRR sequences within a single protein. The predicted signal peptide region (region A) was determined using Wolfpsort (http://wolfpsort.org/; Horton et al. 2007, Nucleic Acids Research (Web Server issue), 35: W585-W587). Dots represent identical amino acid residues; dashes indicate missing amino acids. Cysteine residues are underlined. Gmpgip1, Gmpgip2 and Gmpgip5 are in the pgip locus on chromosome 5. Gmpgip3, Gmpgip4 and Gmpgip7 are on chromosome 8.

Additional file 4: Gene expression patterns of the soybean pgip genes as inferred from expressed sequence tags (ESTs) counts found in public databases ${ }^{a}$.

Additional file 5: Western blot of total protein extract from $N$. benthamiana plants inoculated with PVX-pgip constructs and agarose diffusion assay for PGIP inhibition. A) Western blot analysis was performed using total protein extract from $N$. benthamiana plants inoculated with individual PVX 201-based constructs for the expression of GmPGIP3 or GmPGIP7 or the empty vector, as a control. 1, protein ladder;

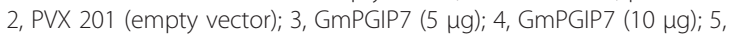
GmPGIP7 $(20 \mu \mathrm{g}) ; 6, \mathrm{GmPGIP3}(10 \mu \mathrm{g})$. B) Agarose diffusion assay using crude protein extract from $N$. benthamiana plants inoculated with the PVX-Gmpgip3 or PVX-Gmpgip7 constructs or the empty vector, as a control. The assay was performed using 0.011 reducing units of S. sclerotiorum endopolygalacturonase (SsPG). The absence of halo indicates the inhibition of PG activity. 1, SsPG; 2, SsPG plus GmPGIP3 $(1 \mu \mathrm{g})$; 3, SsPG plus boiled GmPGIP $(1 \mu \mathrm{g})$; 4, SsPG plus GmPGIP7 $(20 \mu \mathrm{g}) ;$ 5, SsPG plus boiled GmPGIP7 $(20 \mu \mathrm{g}) ; 6$, SsPG plus empty PVX 201 vector $(20 \mu \mathrm{g}) ;$ 7, SsPG plus boiled empty PVX 201 vector $(20 \mu \mathrm{g})$. Similar results were obtained with the PG of F. graminearum, C. acutatum and $A$. niger. GmPGIP3 inhibited to completion all four PGs, whereas GmPGIP7 did not show any inhibition activity (data not shown).

Additional file 6: Alignment of the deduced amino acid sequences of remnant G. max PGIPs. GmPGIP3 was used as reference gene for sequence alignment. Numbering is referred to the GmPGIP3 sequence and starts from the first residue of the mature protein. Regions $A-D$ were predicted according to crystallographic analysis of the bean PVPGIP2 (Di Matteo et al. 2003, Proceedings of the National Academy of Sciences, 100, 10124-10128). The XxLxLxx region is boxed. The predicted signal peptide region (region A) was determined using Wolfpsort (http://wolfpsort.org/; Horton et al. 2007, Nucleic Acids Research Web Server issue), 35: W585-W587). The remnants GMPGIP* (1), which is heavily fragmented, and GMPGIP* (2) are located on chromosome 5. The reconstructed GmPGIP* (1) protein sequence exhibits a putative signal peptide for secretion (region A) and a 299-amino acid mature protein. GmPGIP*(2) corresponds to a 65-amino acid C-terminal fragment. The remnant GmPGIP*, located on chromosomes 8, correspond to a PGIP fragment comprising the putative signal peptide and a 220-amino acid portion of the mature protein. Dots indicate identical amino acids; 
dashes indicate missing amino acids. Empty spaces have been added to better show identity/similarity among LRR sequences within a single protein. Cysteine residues are underlined. *, remnant; Chr, Chromosome.

Additional file 7: Cis-acting regulatory DNA elements related to pathogen-induced expression. The 5 ' flanking region sequence $(\sim 1 \mathrm{~Kb})$ of each Gmpgip gene was analysed using PLACE database (http://www.dna. affrc.go.jp/PLACE/).

Additional file 8: Blast2seq analysis of the region containing the bean pgip genes. A nucleotide sequence limited to $62 \mathrm{~Kb}$ containing the pgip genes (PvBpgip1, PvBpgip2, PvBpgip3, and PvBpgip4) was self-aligned. A red rectangular box represents the Long Tandem Repeats (LTR) retrotransposons. A blue rectangular box represents the specific pgip genes. Ellipses indicate alignments among conserved regions around Pgip genes (blue) and between the two LTR retroelements (red).

Additional file 9: Alignment of the deduced amino acid sequences from $M$. truncatula PGIPs. Numbering is referred to the MtPGIP1 sequence and starts from the first residue of the mature protein. Regions A-D were predicated according to crystallographic analysis of the bean PVPGIP2 (Di Matteo et al. 2003, Proceedings of the National Academy of Sciences, 100, 10124-10128). The $x x L x L x x$ region is boxed. Predicted signal peptide region (region A) was determined using Wolfpsort (http://wolfpsort.org/; Horton et al. 2007, Nucleic Acids Research (Web Server issue), 35: W585-W587). Empty spaces have been added to better show identity/similarity among LRR sequences within a single protein. Dots represent identical amino acid residues; dashes indicate missing amino acids. Cysteine residues are underlined.

Additional file 10: Alignment of the deduced amino acid sequences from C. arietinum PGIPs. CaPGIP1 sequence is numbered starting from the first residue of the mature protein. Regions A-D were predicated according to crystallographic analysis of the bean PvPGIP2 (Di Matteo et al. 2003, Proceedings of the National Academy of Sciences, 100, 10124-10128). The $x x L x L x x$ region is boxed. Empty spaces indicate gaps to maximize identity/similarity between sequences. Predicted signal peptide region (region A) was determined using Wolfpsort (http://wolfpsort.org/; Horton et al. 2007, Nucleic Acids Research (Web Server issue), 35: W585-W587). Empty spaces have been added to better show identity/ similarity among LRR sequences within a single protein. Dots represent identical amino acid residues; dashes indicate missing amino acids. Cysteine residues are underlined.

\section{Competing interests}

The authors declare that they have no competing interests.

\section{Authors' contributions}

RMK carried out the molecular analyses and contributed to the first draft of the paper; AC performed sequence and phylogenetic analyses; CV performed BAC library screening, clones characterization and heterologous expression analyses; DOS, supervised BAC library screening and clones characterization; LS performed infection experiments; FF, FC and GDL critically discussed the data and paper; RD designed the research, coordinated it and wrote the paper. All authors read, edited and approved the final manuscript.

\section{Acknowledgments}

Research supported by MIUR (Ministero dell'Istruzione, dell'Universita' e della Ricerca; grants PRIN [Programmi di Ricerca Scientifica di Rilevante Interesse Nazionale]) to RD and GDL. The authors wish to thank Daniëlle Smeitink for technical support.

The sequence data of the bean genome (P. vulgaris accession G19833) were produced by the US Department of Energy Joint Genome Institute http:// www.jgi.doe.gov/ in collaboration with the user community.

\section{Author details}

'Dipartimento di Scienze e tecnologie per l'Agricoltura, le Foreste, la Natura e l'Energia, (DAFNE), Università della Tuscia, Via S. Camillo de Lellis snc, 01100, Viterbo, Italy. ${ }^{2}$ Bioversity International, Commodity systems \& genetic resources programme, Parc Scientifique Agropolis II, 1990 Boulevard de la Lironde, 34397 Montpellier Cedex 5, France. ${ }^{3} \mathrm{NIAB}$, Huntingdon Road, Cambridge CB3 OLE, UK. ${ }^{4}$ Dipartimento Territorio e Sistemi agro-forestali
(TESAF), Università di Padova, Agripolis, Viale dell'Università 16, 35020 Legnaro (PD), Italy. ${ }^{5}$ Dipartimento di Biologia e Biotecnologie "Charles Darwin", Sapienza Università di Roma, Piazzale Aldo Moro, 5, 00185 Roma, Italy. 'Present address: Enza Zaden Italia Research SRL, S.S. Aurelia km 96.710, 01016 Tarquinia (VT), Italy. ${ }^{7}$ Present address: School of Agriculture, Policy and Development, University of Reading, Whiteknights, Reading RG6 6AR, UK.

Received: 3 March 2014 Accepted: 14 July 2014

Published: 18 July 2014

\section{References}

1. Ten Have A, Mulder W, Visser J, van Kan JA: The endopolygalacturonase gene Bcpg1 is required for full virulence of Botrytis cinerea. Mol Plant-Microbe Interact 1998, 11:1009-1016.

2. Powell AL, van Kan J, ten Have A, Visser J, Greve LC, Bennett AB, Labavitch JM: Transgenic expression of pear PGIP in tomato limits fungal colonization. Mol Plant-Microbe Interact 2000, 13:942-950

3. Ferrari S, Vairo D, Ausubel FM, Cervone F, De Lorenzo G: Tandemly duplicated Arabidopsis genes that encode polygalacturonase-inhibiting proteins are regulated coordinately by different signal transduction pathways in response to fungal infection. Plant Cell Online 2003, 15:93-106.

4. Agüero CB, Uratsu SL, Greve C, Powell ALT, Labavitch JM, Meredith CP, Dandekar AM: Evaluation of tolerance to Pierce's disease and Botrytis in transgenic plants of Vitis vinifera L. expressing the pear PGIP gene. Mol Plant Pathol 2005, 6:43-51.

5. Manfredini C, Sicilia F, Ferrari S, Pontiggia D, Salvi G, Caprari C, Lorito M, De Lorenzo G: Polygalacturonase-inhibiting protein 2 of Phaseolus vulgaris inhibits BcPG1, a polygalacturonase of Botrytis cinerea important for pathogenicity, and protects transgenic plants from infection. Physiol Mol Plant Pathol 2005, 67:108-115.

6. Joubert DA, Slaughter AR, Kemp G, Becker JWW, Krooshof GH, Bergmann C, Benen J, Pretorius IS, Vivier MA: The grapevine polygalacturonaseinhibiting protein (VvPGIP1) reduces Botrytis cinerea susceptibility in transgenic tobacco and differentially inhibits fungal polygalacturonases. Transgenic Res 2006, 15:687-702.

7. Janni M, Sella L, Favaron F, Blechl AE, De Lorenzo G, D'Ovidio R: The expression of a bean PGIP in transgenic wheat confers increased resistance to the fungal pathogen Bipolaris sorokiniana. Mol Plant-Microbe Interact 2008, 21:171-177.

8. Hwang BH, Bae H, Lim H-S, Kim KB, Kim SJ, Im M-H, Park B-S, Kim DS, Kim J: Overexpression of polygalacturonase-inhibiting protein 2 (PGIP2) of Chinese cabbage (Brassica rapa ssp. pekinensis) increased resistance to the bacterial pathogen Pectobacterium carotovorum ssp. carotovorum. Plant Cell Tissue Organ Cult 2010, 103:293-305.

9. Pérez-Donoso AG, Sun Q, Roper MC, Greve LC, Kirkpatrick B, Labavitch JM: Cell wall-degrading enzymes enlarge the pore size of intervessel pit membranes in healthy and Xylella fastidiosa-infected grapevines. Plant Physiol 2010, 152:1748-1759.

10. Volpi C, Janni M, Lionetti V, Bellincampi D, Favaron F, D'Ovidio R: The ectopic expression of a pectin methyl esterase inhibitor increases pectin methyl esterification and limits fungal diseases in wheat. Mol Plant-Microbe Interact 2011, 24:1012-1019.

11. Ferrari S, Sella L, Janni M, De Lorenzo G, Favaron F, D'Ovidio R: Transgenic expression of polygalacturonase-inhibiting proteins in Arabidopsis and wheat increases resistance to the flower pathogen Fusarium graminearum. Plant Biol 2012, 14:31-38.

12. Borras-Hidalgo O, Caprari C, Hernandez-Estevez I, De Lorenzo G, Cervone F: A gene for plant protection: expression of a bean polygalacturonase inhibitor in tobacco confers a strong resistance against Rhizoctonia solani and two oomycetes. Front Plant Sci 2012, 3:268.

13. Jones DA, Jones JDG: The role of leucine-rich repeat proteins in plant defences. Adv Bot Res 1997, 24:89-167.

14. Di Matteo A, Federici L, Mattei B, Salvi G, Johnson KA, Savino C, De Lorenzo G, Tsernoglou D, Cervone F: The crystal structure of polygalacturonase-inhibiting protein (PGIP), a leucine-rich repeat protein involved in plant defense. Proc Natl Acad Sci U S A 2003, 100:10124-10128.

15. Hegedus DD, Li R, Buchwaldt L, Parkin I, Whitwill S, Coutu C, Bekkaoui D, Rimmer SR: Brassica napus possesses an expanded set of polygalacturonase inhibitor protein genes that are differentially regulated in response to 
Sclerotinia sclerotiorum infection, wounding and defense hormone treatment. Planta 2008, 228:241-253.

16. D'Ovidio R, Raiola A, Capodicasa C, Devoto A, Pontiggia D, Roberti S, Galletti R, Conti E, O'Sullivan D, De Lorenzo G: Characterization of the complex locus of bean encoding polygalacturonase-inhibiting proteins reveals subfunctionalization for defense against fungi and insects. Plant Physiol 2004, 135:2424-2435.

17. Kalunke RM, Janni M, Sella L, David P, Geffroy V, Favaron F, D'Ovidio R: Transcript analysis of the bean polygalacturonase inhibiting protein gene family reveals that Pvpgip2 is expressed in the whole plant and is strongly induced by pathogen infection. J Plant Pathol 2011, 93:141-148.

18. D'Ovidio R, Roberti S, Giovanni MD, Capodicasa C, Melaragni M, Sella L, Tosi P, Favaron F: The characterization of the soybean polygalacturonaseinhibiting proteins (Pgip) gene family reveals that a single member is responsible for the activity detected in soybean tissues. Planta 2006, 224:633-645

19. Young ND, Debellé F, Oldroyd GED, Geurts R, Cannon SB, Udvardi MK, Benedito VA, Mayer KFX, Gouzy J, Schoof H, Van de Peer Y, Proost S, Cook DR, Meyers BC, Spannagl M, Cheung F, De Mita S, Krishnakumar V, Gundlach H, Zhou S, Mudge J, Bharti AK, Murray JD, Naoumkina MA, Rosen B, Silverstein KAT, Tang H, Rombauts S, Zhao PX, Zhou P, et al: The Medicago genome provides insight into the evolution of rhizobial symbioses. Nature 2011, 480:520-524.

20. Varshney RK, Song C, Saxena RK, Azam S, Yu S, Sharpe AG, Cannon S, Baek J, Rosen BD, Tar'an B, Millan T, Zhang X, Ramsay LD, Iwata A, Wang Y, Nelson W, Farmer AD, Gaur PM, Soderlund C, Penmetsa RV, Xu C, Bharti AK, He W, Winter P, Zhao S, Hane JK, Carrasquilla-Garcia N, Condie JA, Upadhyaya HD Luo M-C, et al: Draft genome sequence of chickpea (Cicer arietinum) provides a resource for trait improvement. Nat Biotechnol 2013, 31:240-246.

21. Schmutz J, Cannon SB, Schlueter J, Ma J, Mitros T, Nelson W, Hyten DL, Song Q, Thelen JJ, Cheng J, Xu D, Hellsten U, May GD, Yu Y, Sakurai T, Umezawa T, Bhattacharyya MK, Sandhu D, Valliyodan B, Lindquist E, Peto M, Grant D, Shu S, Goodstein D, Barry K, Futrell-Griggs M, Abernathy B, Du J, Tian Z, Zhu L, et al: Genome sequence of the palaeopolyploid soybean. Nature 2010, 463:178-183.

22. Baulcombe DC, Chapman S, Santa Cruz S: Jellyfish green fluorescent protein as a reporter for virus infections. Plant J 1995, 7:1045-1053.

23. Michelmore RW, Meyers BC: Clusters of resistance genes in plants evolve by divergent selection and a birth-and-death process. Genome Res 1998 , 8:1113-1130.

24. De Lorenzo G, D'Ovidio R, Cervone F: The role of polygalacturonase-inhibiting proteins (pgips) in defense against pathogenic fungi. Annu Rev Phytopathol 2001, 39:313-335

25. Stotz H, Bishop J, Bergmann CW, Koch M, Albersheim P, Darvill AG, Labavich $J M$ : Identification of target amino acids that affect interactions of fungal polygalacturonases and their plant inhibitors. Physiol Mol Plant Pathol 2000, 56:117-130.

26. Bishop JG: Directed mutagenesis confirms the functional importance of positively selected sites in polygalacturonase inhibitor protein. $\mathrm{Mol} B \mathrm{Bi}$ Evol 2005, 22:1531-1534.

27. Casasoli M, Federici L, Spinelli F, Matteo AD, Vella N, Scaloni F, Fernandez-Recio J, Cervone F, De Lorenzo G: Integration of evolutionary and desolvation energy analysis identifies functional sites in a plant immunity protein. Proc Natl Acad Sci 2009, 106:7666-7671

28. Leckie F, Mattei B, Capodicasa C, Hemmings A, Nuss L, Aracri B, De Lorenzo G, Cervone $F$ : The specificity of polygalacturonase-inhibiting protein (PGIP): a single amino acid substitution in the solvent-exposed beta-strand/beta-turn region of the leucine-rich repeats (LRRs) confers a new recognition capability. EMBO J 1999, 18:2352-2363.

29. Sicilia F, Fernandez-Recio J, Caprari C, De Lorenzo G, Tsernoglou D, Cervone F, Federici L: The polygalacturonase-inhibiting protein PGIP2 of Phaseolus vulgaris has evolved a mixed mode of inhibition of endopolygalacturonase PG1 of Botrytis cinerea. Plant Physio/ 2005, 139:1380-1388.

30. Farina A, Rocchi V, Janni M, Benedettelli S, De Lorenzo G, D'Ovidio R: The bean polygalacturonase-inhibiting protein 2 (PvPGIP2) is highly conserved in common bean (Phaseolus vulgaris L.) germplasm and related species. Theor Appl Genet 2009, 118:1371-1379.

31. Spinelli F, Mariotti L, Mattei B, Salvi G, Cervone F, Caprari C: Three aspartic acid residues of polygalacturonase-inhibiting protein (PGIP) from Phaseolus vulgaris are critical for inhibition of Fusarium phyllophilum PG. Plant Biol 2009, 11:738-743.
32. Benedetti M, Leggio C, Federici L, De Lorenzo G, Pavel NV, Cervone F: Structural resolution of the complex between a fungal polygalacturonase and a plant polygalacturonase-inhibiting protein by small-angle X-ray scattering. Plant Physiol 2011, 157:599-607.

33. Benedetti M, Andreani F, Leggio C, Galantini L, Di Matteo A, Pavel NV, De Lorenzo G, Cervone F, Federici L, Sicilia F: A single amino-acid substitution allows endo-polygalacturonase of Fusarium verticillioides to acquire recognition by PGIP2 from Phaseolus vulgaris. PLoS One 2013, 8:e80610.

34. Blanc $\mathrm{G}$, Wolfe $\mathrm{KH}$ : Widespread paleopolyploidy in model plant species inferred from age distributions of duplicate genes. Plant Cell Online 2004, 16:1667-1678

35. Schlueter JA, Lin J-Y, Schlueter SD, Vasylenko-Sanders IF, Deshpande S, Yi J, O'Bleness M, Roe BA, Nelson RT, Scheffler BE, Jackson SA, Shoemaker RC: Gene duplication and paleopolyploidy in soybean and the implications for whole genome sequencing. BMC Genomics 2007, 8:330.

36. Jang S, Lee B, Kim C, Kim S-J, Yim J, Han J-J, Lee S, Kim S-R, An G: The OsFOR1 gene encodes a polygalacturonase-inhibiting protein (PGIP) that regulates floral organ number in rice. Plant Mol Biol 2003, 53:357-372.

37. Kanai M, Nishimura M, Hayashi M: A peroxisomal ABC transporter promotes seed germination by inducing pectin degradation under the control of ABI5. Plant J Cell Mol Biol 2010, 62:936-947.

38. Alexandersson E, Becker JV, Jacobson D, Nguema-Ona E, Steyn C, Denby KJ, Vivier MA: Constitutive expression of a grapevine polygalacturonase-inhibiting protein affects gene expression and cell wall properties in uninfected tobacco. BMC Res Notes 2011, 4:493.

39. Nguema-Ona E, Moore JP, Fagerström AD, Fangel JU, Willats WG, Hugo A, Vivier MA: Overexpression of the grapevine PGIP1 in tobacco results in compositional changes in the leaf arabinoxyloglucan network in the absence of fungal infection. BMC Plant Biol 2013, 13:46.

40. Favaron F, Sella L, D'Ovidio R: Relationships among endopolygalacturonase, oxalate, $\mathrm{pH}$, and plant polygalacturonase-inhibiting protein (PGIP) in the interaction between Sclerotinia sclerotiorum and soybean. Mol Plant-Microbe Interact 2004, 17:1402-1409.

41. Miranda Vde J, Coelho RR, Viana AAB, de Oliveira Neto OB, Carneiro RMDG, Rocha TL, de Sa MFG, Fragoso RR: Validation of reference genes aiming accurate normalization of qPCR data in soybean upon nematode parasitism and insect attack. BMC Res Notes 2013, 6:196.

42. Rozen S, Skaletsky H: Primer3 on the WWW for General Users and for Biologist Programmers. In Bioinforma Methods Protoc. Edited by Misener S, Krawetz SA. Totowa, NJ: Humana Press; 1999. 132:365-386.

43. Livak KJ, Schmittgen TD: Analysis of relative gene expression data using real-time quantitative PCR and the 2(-Delta Delta $C(T)$ ) method. Methods 2001, 25:402-408.

44. Cervone F, De Lorenzo G, Degrà L, Salvi G: Elicitation of necrosis in Vigna unguiculata Walp. by homogeneous Aspergillus niger endopolygalacturonase and by a-d-galacturonate oligomers. Plant Physiol 1987, 85:626-630.

45. Favaron F, Castiglioni C, D'Ovidio R, Alghisi P: Polygalacturonase inhibiting proteins from Allium porrum L. and their role in plant tissue against fungal endo-polygalacturonases. Physiol Mol Plant Pathol 1997, 50:403-417.

46. Tomassini A, Sella L, Raiola A, D'Ovidio R, Favaron F: Characterization and expression of Fusarium graminearum endo-polygalacturonases in vitro and during wheat infection. Plant Pathol 2009, 58:556-564.

47. Sambrook J, Fritsch E, Maniatis T: Molecular Cloning: A Laboratory Manual. 2nd edition. Plainview, NY: Cold Spring Harbor Laboratory Press; 1989.

48. Horton P, Park K-J, Obayashi T, Fujita N, Harada H, Adams-Collier CJ, Nakai K: WoLF PSORT: protein localization predictor. Nucleic Acids Res 2007 35(2):W585-W587

49. Higo K, Ugawa $Y$, Iwamoto $M$, Korenaga T: Plant cis-acting regulatory DNA elements (PLACE) database: 1999. Nucleic Acids Res 1999, 27:297-300.

50. Dereeper A, Guignon V, Blanc G, Audic S, Buffet S, Chevenet F, Dufayard J-F, Guindon S, Lefort V, Lescot M, Claverie J-M, Gascuel O: Phylogeny.fr: robust phylogenetic analysis for the non-specialist. Nucleic Acids Res 2008, 36:W465-W469.

doi:10.1186/s12870-014-0189-3

Cite this article as: Kalunke et al.: The pgip family in soybean and three other legume species: evidence for a birth-and-death model of evolution. BMC Plant Biology 2014 14:189. 